\title{
Complement mediated inhibition of immune precipitation in rheumatoid arthritis: studies on interaction of heat aggregated IgG with IgM rheumatoid factor
}

\author{
M M O'SULlivaN, N AMOS, AND B D WILliaMS \\ From the Department of Rheumatology, University Hospital of Wales, Cardiff, Wales
}

\begin{abstract}
SUMmaRY Serum samples from patients with seropositive rheumatoid arthritis contain an inhibitor of complement mediated inhibition of immune precipitation (CMIP). This inhibitory effect can be produced by the addition of either purified monoclonal or polyclonal IgM rheumatoid factor (RF) to human serum. The specificity of the rheumatoid factor influences the degree of inhibition, and when precipitation occurs the rheumatoid factor coprecipitates with the antigen-antibody complex. In rheumatoid sera there was a significant positive correlation between IgM RF concentration and inhibitory activity, though the range of inhibitory activity seen for the same concentration of rheumatoid factor was considerable. Small quantities of heat aggregated IgG (HAGG) had a much greater effect on the measurement in an enzyme linked immunosorbent assay (ELISA) of IgM RF than they did on the inhibitory activity of IgM RF in the CMIP assay. Larger quantities of HAGG initiated complement activation and increased the precipitation of immune complexes. IgM RF reduced the complement activating properties of HAGG by reducing the amount of Clq which bound to the aggregate. The mechanisms by which IgM RF overcomes CMIP in rheumatoid sera may involve its inhibitory effects on the binding of $\mathrm{Cl}$ to the antigen-antibody complex.
\end{abstract}

Key words: immune complexes, monoclonal IgM rheumatoid factor, polyclonal IgM rheumatoid factor.

The reduction of immune precipitation by complement ${ }^{12}$ was shown by Schifferli in 1980 to be due to the activation of the classical pathway of complement. ${ }^{3}$ As a result of this complement activation $\mathrm{C} 3 \mathrm{~b}$ is incorporated into the antigenantigen complex, reducing the lattice formation and thus forming soluble immune complexes. This action of complement is referred to as complement mediated inhibition of immune precipitation (CMIP), and it has been suggested that it plays an important part in preventing the tissue deposition of immune complexes. ${ }^{+6}$

Serum samples from patients with seropositive rheumatoid arthritis are unable to prevent immune precipitation despite having normal or raised levels

Accepted for publication 22 January 1988.

Correspondence to Dr M M O'Sullivan. Department of Rheumatology. University Hospital of Wales, Cardiff CF4 4XW. Wales. of complement. ${ }^{7}$ Furthermore, when heat inactivated serum from these patients is added to normal human serum (NHS) the action of complement in preventing immune precipitation is overcome. ${ }^{8}$ This inhibitory activity can at least be partially attributed to IgM rheumatoid factor as purified IgM RF overcomes CMIP in a concentration dependent manner. ${ }^{9-11}$ In RA sera, however, there is a poor correlation between inhibitory activity and RF concentration, ${ }^{2}$ an observation which suggests that other inhibitory factors are also present that influence its activity. Although inhibitors of CMIP, distinct from IgM RF, have been identified in NHS (Ahmed et al, unpublished data) and rheumatoid sera, ${ }^{13}$ the nature and mode of action of these inhibitors have not been fully elucidated.

Immune complexes which are detectable in RA sera ${ }^{14}$ could bind to IgM RF and interfere with the capacity of IgM RF to overcome CMIP. This paper 
examines the influence of heat aggregated $\operatorname{IgG}$ (HAGG) on the ability of IgM RF to inhibit complement mediated inhibition of immune precipitation.

\section{Materials and methods}

Bovine serum albumin (BSA) was obtained from Sigma Chemical $\mathrm{Co}$ and trace labelled with iodine (125I) by the Iodogen method. ${ }^{15}$ Anti-BSA was produced by immunisation of rabbits with BSA in complete Freund's adjuvant and boosted on day 14 . The resulting antiserum was heat inactivated at $56^{\circ} \mathrm{C}$ for 30 minutes. Equivalence was determined and the antiserum stored in aliquots at $-70^{\circ} \mathrm{C}$ until use.

Monoclonal $\operatorname{IgM}$ RF was obtained from the cryoprecipitate of two patients with mixed cryoglobulinaemia $(\operatorname{IgM} x)$. The washed cryoprecipitate was resuspended in $0.2 \mathrm{M}$ glycine $\mathrm{HCl}(\mathrm{Gly} / \mathrm{HCl})(\mathrm{pH}$ $2 \cdot 8$ ) and purified by chromatography on Sephacryl $\mathrm{S} 300$. The IgM peak was pooled and dialysed overnight against phosphate buffered saline (PBS). Both monoclonal IgM rheumatoid factors were shown by Ouchterlony analysis to contain only IgM and were adjusted to a final concentration of 1 $\mathrm{mg} / \mathrm{ml}$.

Polyclonal IgM RF was obtained from the sera of patients with high titre RF which was absorbed onto Sepharose IgG. After extensive washing with PBS the bound $\mathrm{RF}$ was eluted with $\mathrm{Gly} / \mathrm{HCl}(\mathrm{pH} 2 \cdot 8)$ and further fractionated on an $\mathrm{S} 300$ column in the same buffer. The IgM and IgG peaks were pooled, dialysed against PBS, and stored in aliquots at $-70^{\circ} \mathrm{C}$ until required.

Human $\mathrm{IgG}$ was purified from the pooled sera of normal volunteers by ion exchange chromatography on diethylaminoethyl sephacel equilibrated with $0.02 \mathrm{M}$ phosphate $(\mathrm{pH} \mathrm{7.6)}$ and concentrated by positive pressure to $10 \mathrm{mg} / \mathrm{ml}$. Aggregates were prepared by heating at $63^{\circ} \mathrm{C}$ for 60 minutes and used within 48 hours of preparation.

IgM RF in sera and isolated $\operatorname{IgM}$ rheumatoid factor preparations was measured by an ELISA. ${ }^{16}$

Total haemolytic complement $\left(\mathrm{CH}_{50}\right)$ was measured as previously described. ${ }^{17}$ Sheep red blood cells coated with rabbit antibody (EA) were prepared with haemolytic antisera purchased from Wellcome Laboratories, and the haemolytic complement concentration was calculated from a standard curve using NHS. Clq was purified by euglobulin precipitation ${ }^{18}$ and labelled by the lactoperoxidase method. ${ }^{19}$ Flexible polyvinyl plates and rigid Nunc plates were coated with BSA $10 \mu \mathrm{g} / \mathrm{ml}(100 \mu \mathrm{l} / \mathrm{well})$, $\mathrm{IgG} 10 \mu \mathrm{g} / \mathrm{ml}$, or heat aggregated IgG $10 \mu \mathrm{g} / \mathrm{ml}(100$ $\mu \mathrm{l} / \mathrm{well})$ and incubated at room temperature for two hours. After washing with PBS/Tween, dilutions of
RA sera or purified IgM RF were added and the plate incubated for one hour. The flexiplate wa then washed five times with PBS, and $100 \mu \mathrm{l}$ of radiolabelled Clq ( $1 / 50$ dilution in $1 \mathrm{mg} / \mathrm{ml}$ ovalbus min in complement fixing diluent) was added an incubated for one hour. Bound Clq was measured i a gammacounter (LKB 1282 compugamma). In the rigid plate, peroxidase conjugated antihuman IgMP was added and the ELISA assay for IgM RF carrie $\bar{\Phi}$ out as described previously. ${ }^{16}$

MEASUREMENT OF INHIBITORY ACTIVITY CMIP by NHS was measured as previousR described. ${ }^{3}$ To test for inhibitory activity of CMIA $50 \mu \mathrm{l}$ of heat inactivated test material was firg incubated with $10 \mu \mathrm{l}$ of anti-BSA $(\times 2$ antibody excess;specific antibody $8.4 \mu \mathrm{g})$ at $37^{\circ} \mathrm{C}$ for fiv minutes. A reaction mixture of NHS $(50 \mu \mathrm{l})$ and $\left[{ }^{125} \mathrm{I}\right] \mathrm{BSA}(1.5 \mu \mathrm{g}$ in $5 \mu \mathrm{l})$ for each test was prepare $\vec{\phi}$ added to the above mixture, and further incubat for 20 minutes. The reaction was stopped by the addition of ice cold PBS and centrifugation at 4000 rpm for 10 minutes. The precipitate was thede washed once in PBS and counted in an automat? gammacounter. Percentage precipitation was calc 8 lated as counts in the pellet as a percentage of the total added.

In experiments with HAGG the aggregates we preincubated with purified RF $(25 \mu \mathrm{g})$ for minutes before addition of the anti-BSA.

All experiments were done either in duplicate 웜 triplicate and means obtained. The coefficient $q$ variation was $6 \%$, and experiments were repeated there was a difference of greater than $10 \%$ in th results obtained.

\section{Results}

INHIBITORY ACTIVITY OF RA SERA

Fig. 1 shows the correlation between inhibito $\$$ activity of heat inactivated RA sera (percentage BSA/anti-BSA complexes) and the level of Ig rheumatoid factor (ELISA). Despite a significand positive correlation $(r=0) \cdot 52, p<0 \cdot()() 1)$, sera with similar concentration of rheumatoid factor showed varying levels of inhibitory activity. All inhibito activity of CMIP was removed, however, in selecteg sera after immunoabsorption on Sepharose IgG but not after immunoabsorption on Sepharose 6B (da not shown).

IN HIBITORY ACTIVITY OF MONOCIONAI. RHEUMATOID FACTOR

The capacity of serum complement to inhibit pr疋 cipitation of antigen-antibody complexes can overcome by increasing the quantity of immunge 
complexes added to a fixed volume of serum (Fig. 2 ). At concentrations of immune complexes which are kept soluble by complement CMIP is overcome by the addition of two different monoclonal IgM rheumatoid factors (MRFs). At a BSA concentra-

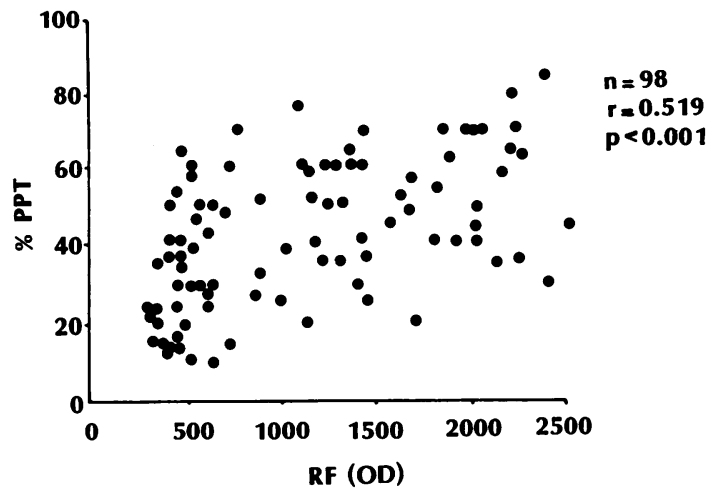

Fig. 1 Correlation between inhibitory activity (percentage precipitation (\% PPT)) and RF concentration (ELISA). 300 optical density $(O D)$ units was the lower limit of normal in the assay. A precipitation of $25 \%$ is taken as evidence of inhibitor present.

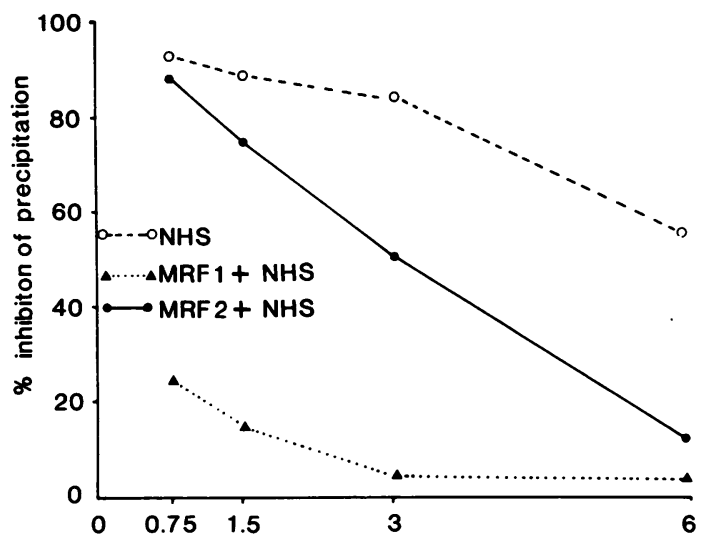

$\mu g$ BSA added

Fig. 2 Comparison of two monoclonal rheumatoid factors. Increasing concentrations of bovine serum albumin (BSA)/anti-BSA immune complexes when added to fixed volume $(50 \mu \mathrm{l})$ of normal human serum $(\mathrm{NHS})$ cause precipitation of complexes (O---O). CMIP was also overcome by the addition of $25 \mu \mathrm{g}$ monoclonal IgM RF (MRF). Although of similar latex titre (1/2000), MRFI had much greater inhibitory activity than MRF2 and had greater affinity to rabbit IgG. (In an ELISA MRFI had 1500 OD units of rheumatoid factor activity compared with $M R F 2$ which had 460 OD units.) tion of $3 \mu \mathrm{g}$, less than $10 \%$ of the immune complexes remained soluble in the presence of MRF1, whereas $50 \%$ of the complexes remained soluble in the presence of MRF2. In an ELISA MRF1 showed greater binding to rabbit IgG (1500 OD units) than MRF2 (460 OD units), though their reactivity with human IgG was similar (latex titre 1/2000).

INFLUENCE OF HAGG ON INHIBITORY

ACTIVITY OF RHEUMATOID FACTOR

Preincubation of MRF1 with HAGG inhibited the measurement of RF by ELISA in a dose dependent manner (Fig. 3a). A similar reduction in the capacity of MRF1 to overcome CMIP was not observed, however. The addition of $6 \mu \mathrm{g}$ HAGG produced a reduction of $50 \%$ in the measured rheumatoid factor but it had no effect on the action of RF on CMIP. The precipitation seen was greater than that seen for an equivalent measured amount of $R F$ in the absence of HAGG, however, and was not due to any precipitation induced by the aggregated IgG itself (Fig. 3b). A reduction in the precipitation induced by RF was only observed when higher amounts of HAGG were used $(>50 \mu \mathrm{g})$, but at these concentrations little or no rheumatoid factor could be detected (ELISA).

INFLUENCE OF RHEUMATOID FACTOR ON COMPLEMENT ACTIVATION BY HAGG

The anticomplementary activity of HAGG, as assessed by its capacity to overcome CMIP, was not observed until quantities of $100 \mu \mathrm{g}$ or more were used (Fig. 4). When these amounts of HAGG were preincubated with MRF1 a reduction in its capacity to overcome CMIP was observed (Fig. 4), and this was due to a reduction in the capacity of these aggregates to activate the complement system as measured by a reduction in the total haemolytic complement activity (data not shown). Additional experiments were carried out to determine whether polyclonal rheumatoid factor also reduced the capacity of HAGG to activate complement. In these experiments HAGG was preincubated with three separate polyclonal rheumatoid factors. The IgM fraction from RA serum, which had been absorbed by Sepharose IgG, was used as a control. Fig. 5 shows that two of the three polyclonal rheumatoid factors reduced the capacity of HAGG to activate complement. No such effect was observed with the control. These three polyclonal rheumatoid factors, when added to human serum, did not change the haemolytic complement titre.

To determine whether this protective effect of rheumatoid factor on complement activation by HAGG was produced by a direct effect on the classical pathway we investigated the effects of $\operatorname{IgM}$ 
RF on the binding of Clq. Both IgM RF and RA serum reduced the capacity of $\mathrm{Clq}$ to bind to HAGG. The binding of Clq was dependent upon the presence of antibody as very little bound to the BSA control (Fig. 6). Preincubation of the aggre- gates with purified polyclonal RF or RA sepa reduced the binding of Clq. An inverse correlation was found between the quantity of $\mathrm{Clq}$ bound ant the IgM RF concentration (Fig. 7).

Rheumatoid factor also reduced the capacity
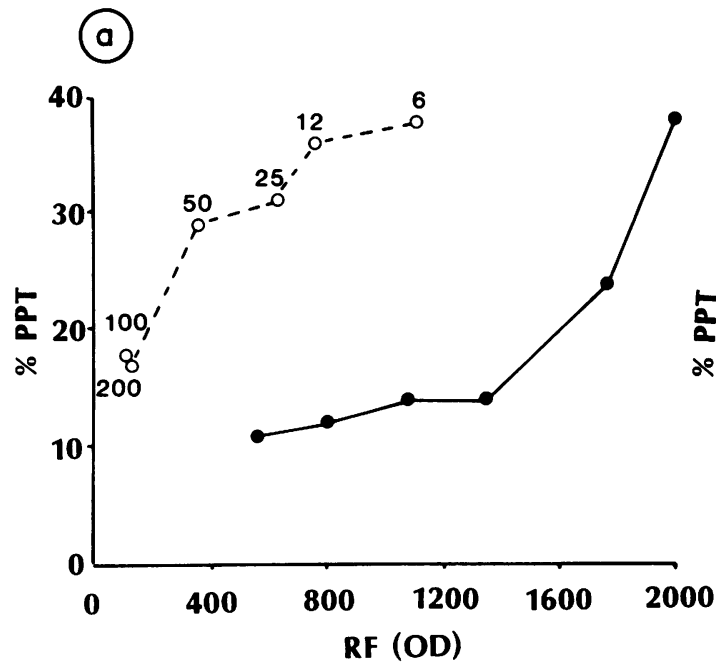

(b)

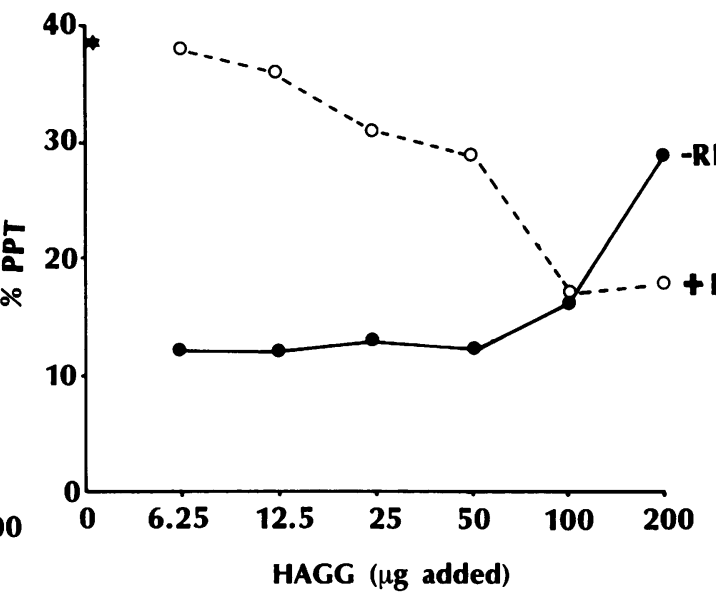

Fig. 3 (a) Influence of heat aggregated IgG $(H A G G)$ on RF measurement and inhibitory activity. Isolated monoclonal IgM RF (doubling dilutions of $25 \mu \mathrm{g}$ ) induced precipitation in a dose dependent manner (-0). When a fixed amount of RF $(25 \mu \mathrm{g})$ was incubated with increasing amounts of HAGG (O---O) RF binding as measured by ELISA was increasingly inhibited, but precipitation was poorly inhibited until $100 \mu \mathrm{g}$ of HAGG was added. Figures on curve (O---O) represent the quantity of HAGG added ( $\mu \mathrm{g})$. (b) HAGG at a concentration of $<100 \mu \mathrm{g} / \mathrm{ml}$ did not induce precipitation of BSA/anti-BSA complexes. At these concentrations they had a slight effect on the precipitation induced by monoclonal IgM RF (-). ${ }^{*}$ Represents percentage precipitation by $R F$ alone.

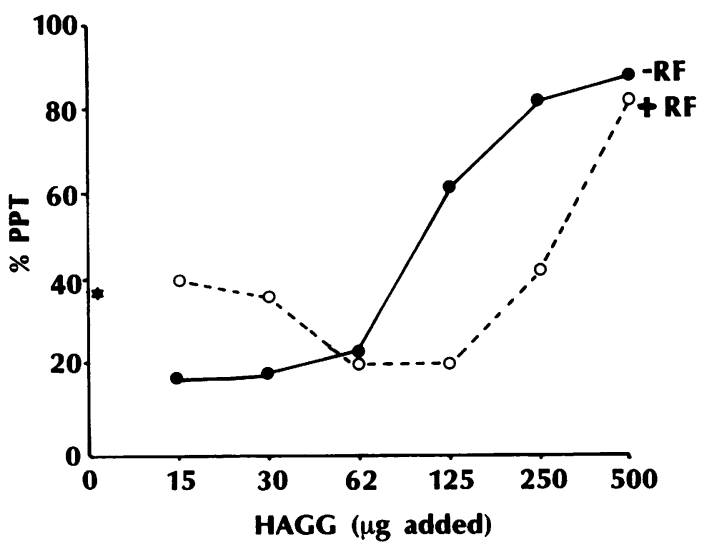

Fig. 4 Influence of RF on HAGG. HAGG $>100 \mu \mathrm{g}$ induced precipitation of BSA/anti-BSA complexes by its anticomplementary activity $(-1)$. Preincubation of these complexes with monoclonal IgM RF resulted in less precipitation (O---O).

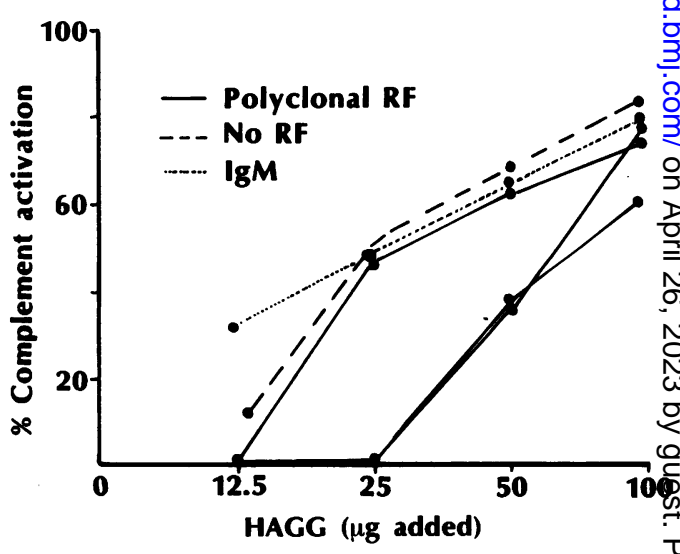

Fig. 5 Complement activation $\left(\mathrm{CH}_{50}\right)$ induced by $\mathrm{HAG} \overrightarrow{\mathrm{B}}$ and polyclonal RF. Two of the three polyclonal RFs reduced the complement activating capacity of $H A G G$ as measured by a reduction in percentage total haemolytic complement. 
Clq to bind to BSA/anti-BSA complexes, which had been formed on the surface of a plate. This reduction in Clq binding was also dependent on the quantity of rheumatoid factor bound to the complex (data not shown).

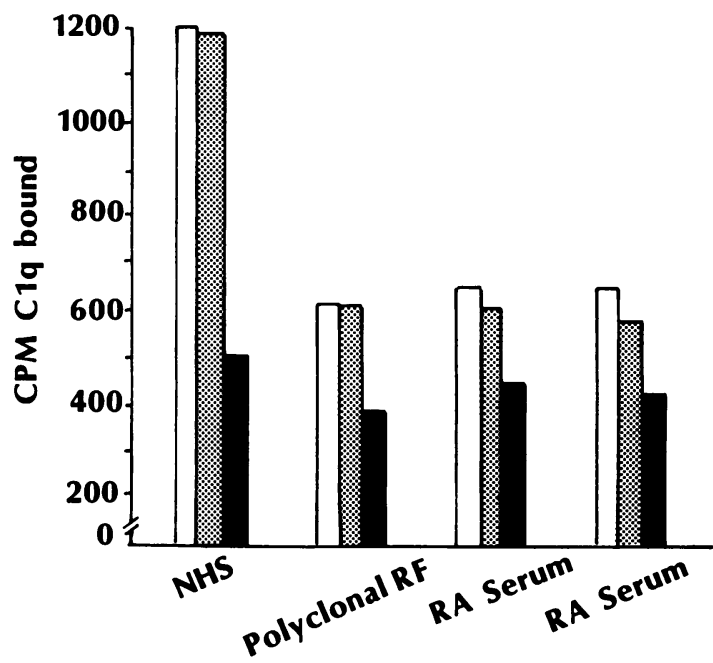

Fig. 6 Binding of Clq to $\operatorname{Ig} G(\square), H A G G$ (国), and BSA (D). In the presence of NHS about $20 \%$ of the added radiolabelled Clq bound to $\operatorname{IgG}$ and $H A G G$ and $8 \%$ to the $B S A$ control. In the presence of polyclonal $R F$ and $R A$ sera there was significantly less binding of $\mathrm{Clq}$ to both $\operatorname{Ig} G$ and $H A G G(50 \%$ reduction in binding).

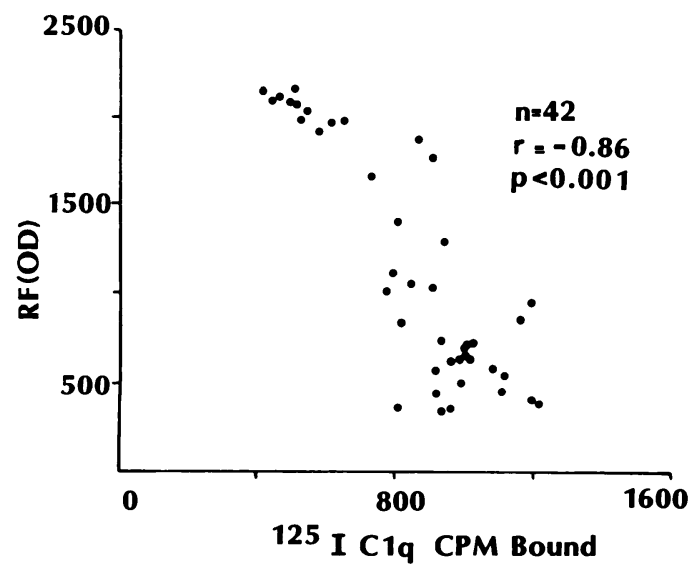

Fig. 7 Correlation between bound IgM RF (OD units) and bound Clq. There was a significant inverse correlation between the IgM RF bound to the HAGG in the wells and the bound Cla.

\section{Discussion}

Our studies with polyclonal and monoclonal rheumatoid factors confirm the observations of others ${ }^{10}$ " that IgM RF can overcome complement mediated inhibition of precipitation and induce precipitation of immune complexes. This effect is not due to rheumatoid factor initiating complement activation but is dependent upon the binding and incorporation of RF into the antigen-antibody complex. ${ }^{9}$ Other workers have also shown that it is only those monoclonal rheumatoid factors which react with human IgG which are able to inhibit CMIP of immune complexes formed with human but not rabbit antibody."

Given that the binding of rheumatoid factor and its incorporation into the antigen-antibody complex is necessary for precipitation, it is surprising that the correlation between the levels of RF and the degree of inhibition of precipitation is relatively poor. Comparable ranges of rheumatoid factor produce widely differing degrees of precipitation from rheumatoid sera.

The experiments with the HAGG show that when the ELISA is used to measure the concentration of rheumatoid factor, small quantities of HAGG are much more able to reduce the detectable levels of rheumatoid factor than they are to inhibit the effects of rheumatoid factor on complement mediated inhibition of immune precipitation. Immune complexes present in rheumatoid sera may therefore influence the measurement of rheumatoid factor, masking its real concentration, and thereby producing a spurious relation between the observed concentration of rheumatoid factor and the degree of inhibitory activity induced by rheumatoid serum.

The influence of rheumatoid factor on larger quantities of HAGG added to serum was interesting in that it could prevent the precipitation which was due to the complement activating properties of these aggregates. This protective effect of rheumatoid factor on HAGG induced complement activation was seen with the monoclonal rheumatoid factor and two of the three purified polyclonal rheumatoid factors tested. This observation was surprising in view of the observations that IgM RF, when complexed to IgG, is itself anticomplementary. ${ }^{2(1)-22}$ Others have also shown that IgM RF can reduce the complement activating capacity of soluble IgG aggregates, and this effect was accompanied by a large increase in aggregate size..$^{23}$

Studies carried out to determine the mechanisms whereby rheumatoid factor prevented complement activation suggested that this was achieved by direct effect on the binding of Clq. When a plate assay was used, in which change in lattice size is not possible, 
RA sera and purified IgM RF reduced the binding of $\mathrm{Clq}$ to both aggregates of human $\operatorname{IgG}$ and complexes of BSA/anti-BSA. Thus if these observations are applicable to the inhibitory effects of IgM RF on CMIP, then the mechanism whereby RF overcomes CMIP may involve blocking the available binding sites for Clq on the $\mathrm{IgG}$ molecule.

Recent observations suggest that rheumatoid factor may not be the only protein capable of precipitating immune complexes from serum. A 60 kilodalton glycoprotein has been isolated from RA sera and shown to be capable of inhibiting the binding of $\mathrm{Clq}$ to the $\mathrm{Fc}$ fragment of immunoglobulin. ${ }^{24}$ Further investigation is clearly necessary to assess the contribution of each of these factors in overcoming complement mediated inhibition of immune precipitation in rheumatoid arthritis.

\section{References}

1 Morgan C R. Sorenson R L. Lazorow A. Further studies of an inhibitor of the two antibody immunoassay system. Diabetes 1964; 13: 579-84.

2 Grant D B. Observation of the precipitin reaction in a double antibody immunoassay for insulin. Acta Endocrinol (Copenh) 1968: 59: 139-49.

3 Schifferli J A. Bartolotti S R. Peters D K. Inhibition of immune precipitation by complement. Clin Exp Immunol 1980; 42: $387-94$.

4 Schifferli J A. Woo P. Peters D K. Complement mediated inhibition of immune precipitation. I. Role of the classical and alternative pathways. Clin Exp Immunol 1982: 47: 555-62.

5 Schifferli J A, Stciger G, Hauptamm G, Spacth P J, Sjoholm A G. Formation of soluble immune complexes by complement in sera of patients with various hypocomplementaemic states. $J$ Clin Invest 1985; 76: 2127-33.

6 Schifferli J A. Peters D K. Complement, the immune-complex lattice and the pathophysiology of complement deficiency states. Lancet 1983; ii: 957-9.

7 Naama J K, Mitchell W S. Zoma A. Veitch J. Whaley K. Complement mediated inhibition of immune precipitation in patients with immune complex diseases. Clin Exp Immunol 1983: 51: 292-8.

8 Naama J K. Mitchell W S. Whaley K. Inhibition of complement mediated solubilization of antigen-antibody complexes by serum from patients with rheumatoid arthritis. Clin Exp Immunol 1983: 54: 429-38.

9 O'Sullivan M M. Amos N. Williams B D. Rheumatoid factor inhibits the ability of serum to maintain antigen-antibody complexes in solution. |Abstract|. Br J Rheumatol 1985; 24: Abstr 83.

10 Balestricri G. Tincani A, Miglionini P. Ferri C. Cattanco R. Bombardieri S. Inhibitory effect of IgM rheumatoid factor ono immune complex solubilization and inhibition of immunc등 precipitation. Arthritis Rheum 1984; 27: 1130-6.

11 Mitchell W S. Naama J K. Veitch J. Whaley K. IgM-RF prevents complement mediated inhibition of immune precipitation. Immunology 1984: 52: 445-8.

12 Naama J K. Mitchell W S, Lewis D. Hunter J. Whaley K. ڤ్ Inhibition of immune precipitation in rheumatic disease. Scand $\vec{O}$ J Rheumatol 1984: 13: 193-7.

13 Niven I P. Whalcy K. Inhibition of Clq binding to antigen $\overrightarrow{\vec{C}}$ antibody complexes by a factor in RA serum. Rheumatol $\ln t \mathrm{O}$ 1986: 6: $205-8$.

14 McDougal J S. Hubbard M. McDuffic F C, Strobel D L. Smithō $\mathrm{S} \mathrm{J}$, et al. Comparison of 5 assays for immune complexes in the' rheumatic diseases. II. An assessment of their validity in RA. Arthritis Rheum 1982: 25: 1156-66.

15 Fraker P J. Speck J C. Protein and cell membrane iodinations o with a sparingly soluble chloroamide 1,3,4,6-tetrachloro-3a.6a- $v$ diphenylglycoluril. Biochem Biophys Res Commun 1978; 80:음 849-57.

16 Faith A. Pontesilli O. Unger A. Panayi G S. Johns P. ELISAT assay for IgM and IgM rheumatoid factors. J lmmunol Methods 1982: 55: 169-77.

17 Mayer M M. Complement and complement fixation. In: Kabat E A. Mayer M M. eds. Experimental immunochemistry Springficld. Illinois: Thomas. 1961: 133-45.

18 Yonemasu K. Stroud R M. Clq:rapid purification method for preparation of monospecific antisera and for biochemical studies. J Immunol 1971: 106: 304-13.

19 Morrison M. Bayse G S. Catalysis of iodination by lactoperox idase. Biochemistry 1971: 9: 2995-30(00.

20 Zvaifler N J. Schur P H. Reaction of aggregated mercaptoctha nol treated gammaglobulin with rheumatoid factor-precipiting and complement fixation studies. Arthritis Rheum 1968; 11: $523-36$.

21 Taylor-Upsahl M M. Johnson P M. Mellbyc O J. Natvig J B. A study of complement fixation by rheumatoid factor using hacmolytic assay system. Clin Exp Immunol 1977; 28: 204-11-7

22 Sabharwal U K. Vaughan J H. Fong S. Bennett P H. CarsonD A. Curd J G. Activation of the classical pathway o巳 complement by rheumatoid factors. Arthritis Rheum 1982; 25? $161-7$

23 Dockes G. Schouter J. Cats A. Daha M R. Reduction of the complement activation capacity of soluble $\lg G$ aggregates and immunc complexes by IgM rheumatoid factor. Immunolog. 1985: 55: 554-64.

24 Ahmed A E, Whaley K. Characterisation and mechanism of action of a serum inhibitor of complement mediated prevention of immune precipitation |Abstract|. Br J Rheumatol 1987: 260 (suppl 2): 181 